Sharif University of Technology
Scientia Iranica

\title{
A comparative analysis of the new excitation controlled synchronous generator-based wind turbine
}

\author{
A. Shamsnia* and M. Parniani \\ Department of Electrical Engineering, Sharif University of Technology, Tehran, Iran.
}

Received 3 July 2018; received in revised form 15 July 2019; accepted 16 September 2019

\author{
KEYWORDS \\ Wind turbine \\ configuration; \\ Excitation controlled \\ synchronous \\ generator-based wind \\ turbine; \\ Diode bridge \\ rectifier-based wind \\ turbine; \\ Wind turbine \\ efficiency; \\ Wind turbine cost; \\ DC grid offshore wind \\ farm.
}

\begin{abstract}
Excitation Controlled Synchronous Generator-based Wind Turbine (ECSG WT) is a recently proposed Wind Turbine (WT) scheme that has not been fully investigated in detail. This paper intends to analyze the performance of the ECSG WT scheme and compare it with those of two mainstream WT schemes based on electrically excited synchronous generator, i.e., VSC-based full converter WT and diode bridge rectifier-based WT equipped with boost converter on its Direct Current (DC) link. The objective of this comparison is to demonstrate great potentials of ECSG WT to be considered in the wind industry. To do so, two successful Wind Turbine (WT) schemes in the market that are structurally close to ECSG WT are selected. The comparison includes different technical and economic aspects of the three schemes, assuming the DC grid connection for the WTs. In addition, another comparison is made between the recently introduced Siemens 2ndgeneration DC grid access offshore wind farm and a wind farm with a similar structure using ECSG WTs. The results of these comparisons show that the ECSG WT scheme enjoys promising characteristics in economic, reliability, and efficiency terms.
\end{abstract}

(C) 2022 Sharif University of Technology. All rights reserved.

\section{Introduction}

Wind Farms (WFs) can be located either onshore or offshore. Onshore wind resources are limited. Besides, onshore WFs face several problems such as noise, tower shadow and visual impacts for neighboring residents, protests from environmental protection groups, and transportation of large components. Accordingly, the wind industry has considered offshore development of WFs during the last decade as an alternative since offshore has vast sources of more powerful and more stable winds, where transportation of large components

\footnotetext{
*. Corresponding author. Tel.: +982166165973; +9821 66165963

E-mail addresses: shamsnia_ali@ee.sharif.ir (A. Shamsnia); parniani@sharif.edu (M. Parniani)
}

is easier, making employment of larger Wind Turbines (WTs) possible [1-5]. For example, in Europe, the cumulative installed offshore wind capacity had grown from $36 \mathrm{MW}$ in 2000 to $6562 \mathrm{MW}$ by the end of the year 2013 and estimations show that this capacity reaches up to 40 GW by 2020. Furthermore, it is forecasted that $150 \mathrm{GW}$ of offshore WF capacity is operational at 2030, meeting $14 \%$ of Europe electricity consumption [6].

On the other hand, in terms of WT scheme, Doubly-Fed Induction Generator (DFIG) based WTs represent an ideal choice for onshore WFs demanding WTs to be below $5 \mathrm{MW}$ capacity $[1,7-9]$. The prime advantage of DFIG is the reduced cost of its partially rated converter. However, the limited range of speed control, use of slip rings with compromised reliability, insufficient power controllability in the case of grid or generator disturbances, and necessity of a strong grid to connect with during the startup are the main 
drawbacks of DFIG scheme. Moreover, DFIG-based WTs contribute to the short-circuit current during a grid fault, because the stator is directly coupled to the grid. Finally, DFIG scheme requires a multistage (usually three-stage) gearbox between its turbine and generator. The feasible limit for an industrial three-stage gearbox with an acceptable weight and size is about $5 \mathrm{MW}$ due to high torque requirements at very low speeds [3,9-12]. In fact, to increase WT power rating, it is necessary to increase its blade radius, but noise and load concerns impose an upper limit on the tip speed of blades. This parameter restricts the rotational speed of turbine $(\omega)$ as the power rating increases. Therefore, according to the turbine shaft torque relation $\left(T_{S}=P / \omega\right)$, very high torques are resulted for high power DFIG WTs that must be handled by the WT gearbox. Considering all these restrictions, WT manufacturers have approached alternative schemes for their high power rated WTs and considered Synchronous Generator (SG)-based WT configurations with a full rated power converter as the main solution. For example, Siemens moved from DFIG to Direct Drive (DD) SG in $6 \mathrm{MW}$ SWT-6.0120 WT. This strategy was also adopted by others like GE, Hyundai, Mitsubishi, Alstom, Nordex, and AMSC. As another example, Bard Company changed configuration from DFIG to medium-speed simplified gearbox SG WT in Bard 6.5. Areva, Gamesa, and Vestas were the others using the same scheme [7,9,12$14]$.

Currently, Permanent Magnet Synchronous Generator (PMSG) WTs and Electrically Excited Synchronous Generator (EESG) WTs are the clear trend in the above $5 \mathrm{MW}$ capacity range and WTs of up to $8 \mathrm{MW}$ capacity with such generators are commercially available $[1,2,7,8]$. Presently, most of SG-based WTs in the market use back-to-back Voltage Source Converters (VSCs) as power conversion unit, which interfaces the SG stator terminal with the AC grid. A major disadvantage of such a WT is that the converter must process the entire SG power, while DFIG requires only about $30 \%$ of the WT power to be processed by the converter. In fact, the requirement for two full rated VSCs has been considered as a significant economic disadvantage for this scheme $[8,12]$. Therefore, adopting a low-cost converter for full-converter SG-based WTs remains a focus of study for long time, and employment of Diode Bridge Rectifier (DBR) as the SG side converter has been found to be an attractive solution. However, DBR-VSC SG WT scheme was not so successful due to such problems as limited operational wind speed range. Accordingly, few industrial applications of this scheme are reported such as Clipper Liberty 2.5 MW WT $[8,14]$. Another DBR-based SG WT scheme employs a boost converter on its Direct Current (DC) link to overcome the limited operational wind speed range of the former type. The DBR-Boost-VSC SG WT scheme was first developed by the Spanish Company MADE and later, it gained widespread popularity in the WT industry [14,15]. At the moment, Enercon uses this scheme for some of its products, like E66/E70/E82 WTs or E82-E3 WT. Other industrial applications of this scheme include Vensys V70/77/82/87 WTs and Gold Wind GW70/77 WTs [1,8,14]. Finally, $10 \mathrm{MW}$ Britannia WT developed by Clipper is an upcoming sample of DBR equipped SG WTs which is currently under development and will be used in "Round Three" WFs of U.K. offshore wind power projects [1].

On the other hand, for economic reasons related to the WF construction and maintenance costs and according to the environmental conditions of offshore, the offshore WF technology tends continuously to higher capacity WTs, pushing offshore WT ratings to above $10 \mathrm{MW}$ range. In the meantime, the feasibility studies conclude that application of the current SG technology for the next-generation WTs, especially DD ones, results in extremely large and heavy WTs that are impractical and uneconomical. Therefore, requirement for a new electrical generator technology with higher torque density is clear in order to design the next-generation DD WTs with reasonable dimensions and weight $[2,4,8,9,15]$. Application of superconductor technology to the field winding of SGs has been considered as an appropriate solution to this problem, and pilots of such WTs are passing the final steps of their experimental use $[1-5,8,13]$. It was estimated that superconductor SG WTs would be commercially available in in 2020, forming $1 \%$ of the annual WT installations worldwide; by 2030, their share will grow up to $18 \%$ [16].

Considering the current state and future trend of EESGs in WT technology, the Excitation Controlled Synchronous Generator-based Wind Turbine (ECSGWT) scheme has been developed recently based on the idea of employing EESG excitation current as a means of WT control [17]. This scheme eliminates the requirement for a VSC at the $\mathrm{SG}$ terminal of WT to perform its control task and replaces it with a simple DBR. Obviously, the ECSG WT scheme suggests a simpler and more economic converter than the conventional back-to-back VSC SG WTs and it can be considered as a preferable alternative for all WTs equipped with EESG. It is to be noted that the EESG-based WTs in the market cover a rated power range of $1.65 \mathrm{MW}$ up to $7.5 \mathrm{MW}$ and several manufacturers like Enercon, E.N.O Energy, Kenersys, and M. Torres develop them [8]. Since ECSG WT scheme has never been deeply investigated before, this paper aims to make a comprehensive comparison between this WT scheme and two other commercial WT schemes to demonstrate great potentials of ECSG WT. This comparison includes all technical and economic aspects 
of importance and it helps judge the ECSG WT scheme more precisely. The competitive WT schemes have been chosen based on two main criteria: (1) In order to be comparable, it should belong to the class of EESG-based WTs; and (2) It should be commercially proven and employed by well-known manufacturers. Accordingly, VSC-VSC SG WT and DBR-Boost-VSC SG WT schemes are chosen for this purpose. VSC-VSC $\mathrm{SG}$ WT is the main stream scheme between EESGbased WT schemes and DBR-Boost-VSC SG WT is the most popular scheme among the EESG-based WTs equipped with DBR $[1,8,14,15]$.

In the following section, the three WT schemes under study are introduced in detail. Section 3 elaborates the technical aspects of these WTs. Sections 4 and 5 compare them in terms of cost and efficiency. Section 6 is devoted to another comparison, including ECSG-based DC grid offshore WF and the Siemens 2nd-generation DC grid access offshore WF. Finally, Section 7 concludes this paper.

\section{WT schemes under study}

In this section, the three WT schemes subjected to the analysis in this paper are introduced in detail. Since all of the three schemes employ exactly the same VSC converters on the grid side for AC grid connection, these converters are excluded from the comparison and DC grid-connected type of the WTs (up to the WTs converter unit DC link) is considered. The other reason for this selection is that the offshore WF industry is proceeding toward DC grid WFs $[6,7,18,19]$ and the new ECSG WT scheme is more appropriate for such WFs than the AC grid ones. On the other hand, a common generator is used for the three WT schemes to make a fair comparison. This generator is a $5 \mathrm{MW}$ 6-phase EESG whose 3-phase module details are given in Table 1 [14].

\subsection{VSC SG WT scheme}

The VSC SG WT is, in fact, a conventional back-toback full converter WT without grid side VSC due to DC grid connection. Since the EESG given in Table 1 used for this study is a 6-phase generator, two 3-phase VSC modules are to be considered for connecting the

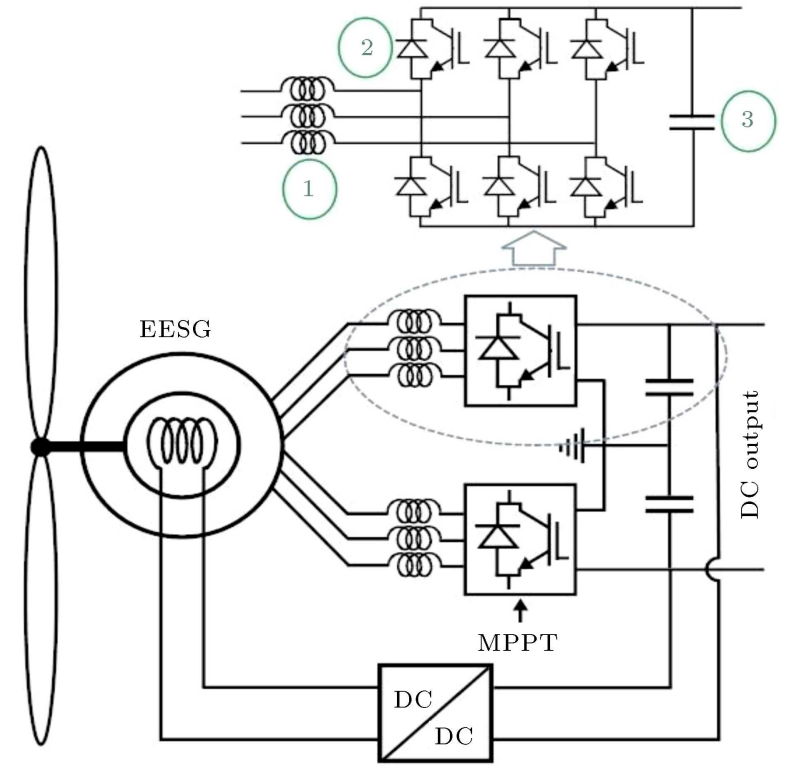

Figure 1. VSC SG WT with 6-phase Electrically Excited Synchronous Generator (EESG) and Direct Current (DC) grid connection.

generator to the local grid, as shown in Figure 1. Such a modular configuration is common for large industrial WTs. The main control task assigned to the remaining VSCs is the implementation of Maximum Power Point Tracking (MPPT) to control the generator line current according to the WT MPP curve $[1-3,8,18]$. In this WT, each 3-phase module has a DC link voltage of 6.5 $\mathrm{kV}$ and their series connection on the $\mathrm{DC}$ side gives rise to $13 \mathrm{kV}$ output voltage for the WT.

For this configuration, IGBT switches of the two VSCs are chosen with $6.5 \mathrm{kV}, 500$ A ratings [20]. Also, the 3-phase module DC link capacitors are selected such that WT DC link voltage ripple is below $5 \%$ in the entire operation range, which has resulted in $1000 \mu \mathrm{F}$, $7 \mathrm{kV}$ capacitors for the modules. Finally, AC side filter inductances of the two modules are $15 \mathrm{mH}$ and restrict the generator line current THDs to $5 \%$. The VSC IGBTs are switched at $1 \mathrm{kHz}$ rate.

\subsection{The new ECSG-based WT scheme}

As mentioned earlier, the proposed scheme employs the excitation current of EESG for the purpose of WT con-

Table 1. 5 MW EESG'S 3-phase module details.

\begin{tabular}{cccc}
\hline Parameter & Value & Parameter & Value \\
\hline Rated apparent power & $3.38 \mathrm{MVA}$ & Stator phase resistance & $0.00513 \mathrm{p} . \mathbf{u}$ \\
Rated power factor & 0.739 & $d$-axis synchronous inductance & $1.061 \mathrm{p} . \mathbf{u}$ \\
Rated line-to-line voltage & $4.0 \mathrm{kV}$ & $q$-axis synchronous inductance & $0.378 \mathrm{p} . \mathbf{u}$ \\
Rated stator current & $485 \mathrm{~A}$ & Stator leakage inductance & $0.1 \mathrm{p} . \mathbf{u}$ \\
Rated frequency & $40 \mathrm{~Hz}$ & - & - \\
Rated core eddy current loss & $30 \mathrm{~kW}$ & Rated core hysteresis loss & $15.5 \mathrm{~kW}$ \\
\hline
\end{tabular}




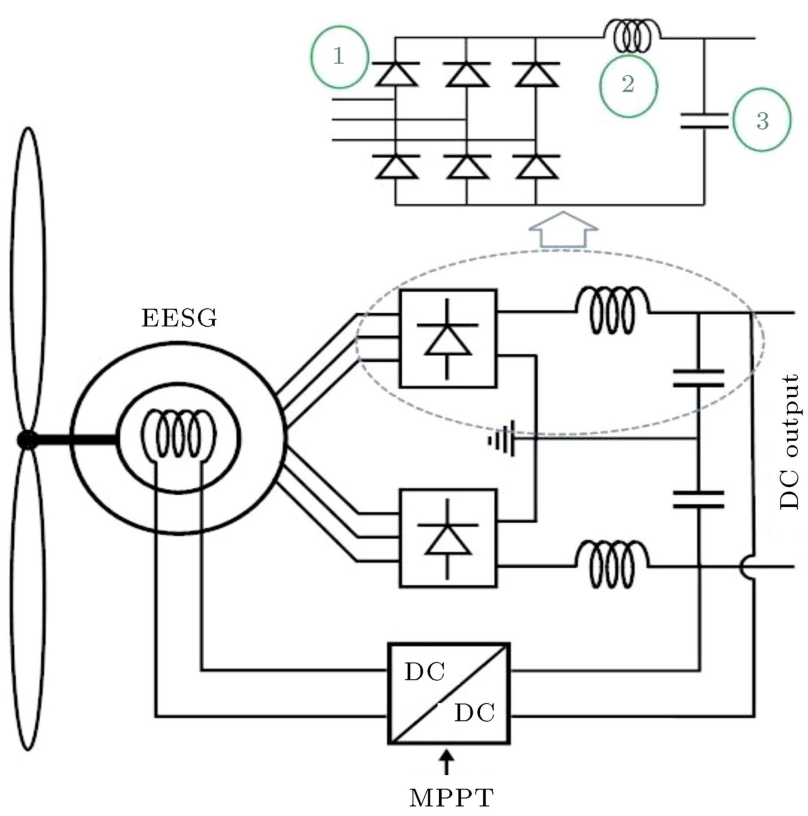

Figure 2. 12-pulse rectifier ECSG-based WT with Direct Current (DC) grid connection.

trol. Thus, the generator output converter is reduced to a simple DBR instead of a costly VSC. The 6-phase EESG of Table 1 is configured as shown in Figure 2 to form a 12-pulse rectification system with two 3phase modules connected in series on the DC side. As discussed later, this rectification system reduces the SG torque ripple by elimination of the generator major harmonic magnetic fields. The proposed configuration delivers $10 \mathrm{kV}$ rated output voltage and the $\mathrm{DC} / \mathrm{DC}$ excitation converter fed from its terminal performs MPPT by regulating the excitation current.

DC link capacitor of each ECSG WT 3-phase converter module has the same capacity as the VSC SG WT modules $(1000 \mu \mathrm{F})$. However, its operating voltage is reduced to $5 \mathrm{kV}$; thus, the voltage rating of ECSG WT capacitors can be chosen $5.5 \mathrm{kV}$. These capacitors limit the ECSG WT DC link voltage ripple to below $5 \%$ in the entire operation range of the WT. On the other hand, DBR leg diodes of this WT are selected with peak reverse voltage of $6.5 \mathrm{kV}$. According to the simulation results, $450 \mathrm{~A}$ current rating will suffice for these diodes; however, the closest rating among the commercially available Infineon products is $6.5 \mathrm{kV}$ 770 A [20]. Since the difference in the price of the diodes is not so influential, this rating is chosen for the ECSG WT DBRs. Finally, the DC link inductances of ECSG WT are designed such that the DC link current ripple is limited to $5 \%$. This results in $75 \mathrm{mH}$ inductors with 500 A current rating.

\subsection{DBR-Boost SG WT scheme}

DBR-Boost SG WT is a DBR-based SG that uses a $\mathrm{DC} / \mathrm{DC}$ boost converter on its DC link as a means of

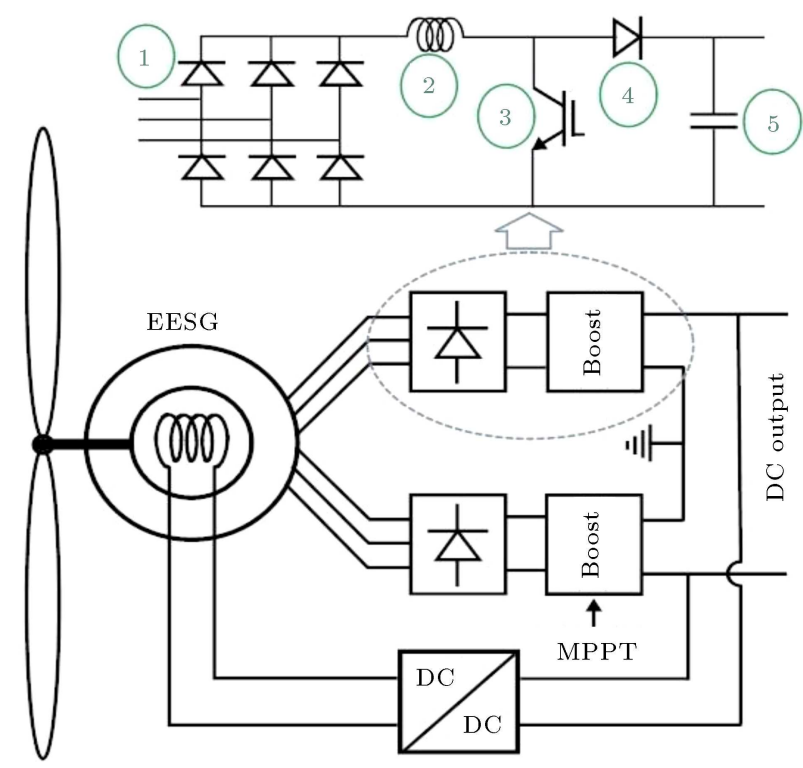

Figure 3. 12-pulse rectifier DBR-Boost SG WT scheme with Direct Current (DC) grid connection.

WT generator current control. This boost converter usually takes the responsibility of performing MPPT $[1,2,8,14]$. Construction of such a WT with the 6 -phase EESG in Table 1 results in a WT, schematically shown in Figure 3. This WT also benefits from a 12-pulse rectification system by series connection of its 3 -phase modules DC side $[8,14,18]$. As is seen, this scheme has a structure similar to the ECSG WT of Figure 2. The main difference between the two is that ECSG WT is controlled through the generator excitation current, while in BDR-Boost SG WT, excitation current is constant and instead, an additional boost converter controls the WT. The other difference lies in the unity power factor problem to be discussed later in Section 3. DBR-Boost SG WT suffers from this problem, but the ECSG WT is immune to it. Thus, DBR-Boost SG WT generator and converter must have higher current ratings than those of ECSG WT $[18,21]$.

Since the diodes considered for the ECSG WT have higher current rating than required, they can be used for DBRs of the DBR-Boost SG scheme. On the other hand, the inductor and the capacitor employed for its converter are chosen with the same size as the ECSG WT converter $(1000 \mu \mathrm{F}$ and $75 \mathrm{mH})$, while the inductor current rating is upgraded to $700 \mathrm{~A}$ (according to the simulation results and because of the unity power factor problem, the peak DC link inductor current of DBR-Boost SG reaches more than $650 \mathrm{~A}$ ). In addition, the capacitor voltage rating needs to be at least $6.0 \mathrm{kV}$ (each 3-phase module boost converter has $6.0 \mathrm{kV}$ output voltage). Besides, the switching rate of boost converters is selected so that the inductor current ripple can be limited to below $5 \%$. This results in 1.2 $\mathrm{kHz}$ switching frequency. The boost converter switch 
must be able to withstand the module output voltage $(6.0 \mathrm{kV})$ and inductor peak current $(650 \mathrm{~A})$. Thus, 6.5 $\mathrm{kV}, 750$ A IGBTs are suitable for this purpose [20]. Finally, $6.5 \mathrm{kV}, 750 \mathrm{~A}$ fast recovery diodes are employed for boost converters of this WT since they commutate with the same switching rate as the IGBTs. It is also noted that the boost converters are designed to work in the continuous conduction mode in the entire operation range of WT.

\section{Technical evaluations}

In this section, the WT configurations introduced in Section 2 are briefly compared in terms of technical aspects of their operation.

\subsection{Generator torque ripple}

Use of DBR at the terminal of an SG-based WT results in non-sinusoidal stator currents, which cause harmonic magnetic fields in the SG air gap rotating at non-synchronous speeds. The interaction between these fields and the rotor field of SG (rotating at a synchronous speed) results in rotor torque ripples, which in turn cause vibration, torsional resonances, and fatigue stress on mechanical structure, especially in DD WTs. For example, in a 6-pulse DBR SG WT, the stator currents contain non-triplen odd harmonics, 5thand 7 th-order harmonics being the major ones with magnitudes of about $14 \%$ and $7 \%$ of the fundamental component, respectively. In the 3 -phase system, the 5 th-order harmonic currents are of negative sequence and create a magnetic field rotating in reverse direction of the main field with 5 times its speed. On the other hand, 7th-order harmonic currents are of positive sequence, with the resultant magnetic field rotating in the same direction of the main field with 7 times its speed. Thus, in terms of rotor, each of these harmonic magnetic fields rotates with a speed 6 times the synchronous speed, but in reverse directions with respect to each other. The resultant magnetic field of these two rotating magnetic fields is a stationary sinusoidal field with a frequency of 6 times the synchronous frequency. Interaction between this pulsating magnetic field and DC field of rotor winding results in 6th-order torque ripple of the generator with an approximate magnitude of $10 \%$. The same situation exists for the 11 th and 13 th as well as other higher order harmonics $[8,14]$. Mathematical analysis of this phenomenon for the 11 th and 13th harmonics is presented in the Appendix.

A suitable solution employed to mitigate this torque ripple to an acceptable level is utilization of 12-pulse, 24-pulse, or higher-order rectification systems using an SG with higher phase number and appropriate phase shift between its 3 -phase modules. For example, in the 12-pulse rectification system, 30 electrical degrees phase shift between the two 3-phase
SG modules causes the 5th and 7 th order harmonic magnetic fields of the two modules to have the same magnitudes but opposing phases in the machine air gap; thus, they cancel out each other. In this way, the major torque ripple component of the 6-pulse system along with 18 th, 30 th and $(2 k+1) \times 6$ order torque ripples is eliminated in the 12-pulse system, resulting in a smoother operation. This solution is completely practical since multi-phase SGs are common in WT technology $[3,9,15]$. In particular, the 12 -pulse rectification system has been widely used in industry and reported in the literature for DBR-Based SG WTs $[8,14,18,19]$. The same remedy has been employed in this paper for ECSG and DBR-Boost SG WTs; then, the three WTs are simulated under different loadings and their torque ripples are compared against each other. Specifically, 12-pulse ECSG WT, 12-pulse DBR-Boost SG WT, and VSC SG WT with the configurations shown in Figures 1-3 generate an appropriate magnitude for DC voltage sources and then, they are simulated for loadings from $5 \%$ to $100 \%$ (at $5 \%$ increment steps). At each loading, WT steady-state operation conditions are reached, the torque ripple of the generator is analyzed by Fourier transformation, and its main and harmonic components are decomposed. Then, TWD of WT generator torque ripple is calculated using Eq. (1). It is noted that the main component of the generator torque is its DC component and the remaining content is considered as harmonics:

$$
\text { Torque } T W D=\frac{\sum_{h} T_{h}}{T_{D C}} \times 100,
$$

where:

$T_{h} \quad$ Generator torque harmonic component $h$

$T_{D C} \quad$ Generator torque DC component

The results of these calculations are shown in Figure 4. As illustrated by the results, even though VSC SG WT has the smoothest operation, the ECSG and DBR-Boost SG WTs present a satisfactory op-

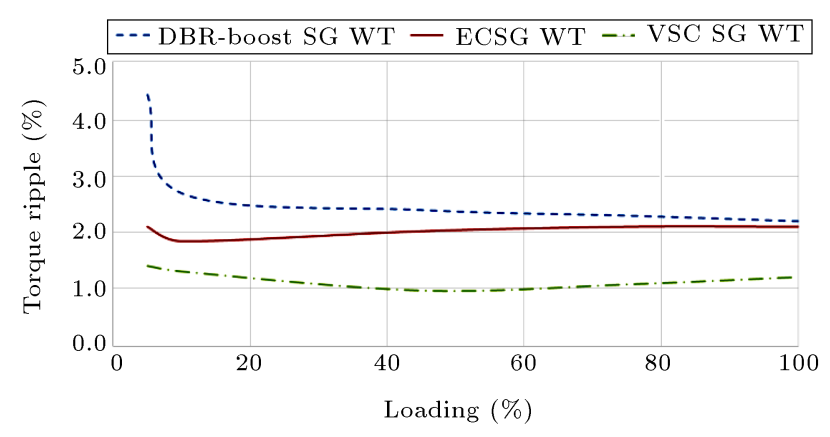

Figure 4. Torque ripple comparison of the three Wind Turbines (WTs) at entire operational range using torque TWD. 
eration, too. In fact, employing a 12-pulse rectification system for DBR-Based SG WTs has resulted in reducing their torque ripple level from $10 \%$ in the 6 pulse rectification mode to about $2 \%$ and therefore, the torque ripple problem is no longer an influencing problem.

\subsection{Unity power factor problem}

In the SG-based WT equipped with DBR, the inability of the passive rectifier to delay its conduction forces the SG terminal to operate at unity power factor. In this situation, if synchronous reactance of the SG was low, the terminal and air-gap power factors would be close to each other. However, SGs typically have a significant synchronous reactance, resulting in low airgap power factors in heavy load conditions. Then, while the fundamental components of terminal voltage and current are in phase and the stator e.m.f and current are close to the rated values, a considerable voltage decline at stator synchronous reactance reduces terminal voltage. Consequently, the SG terminal active power is limited to below the rated value even under rated stator current, and the increased operating current is required to overcome this limitation $[18,21]$.

A remedy used for this problem in industrial DBR equipped WT generators is to redesign the SG such that its synchronous reactance is reduced. Another solution is employment of a generator and a converter with higher current rating for such WTs [21]. Both of these corrections yield a more expensive system that annuls cost saving for a part of DBR-equipped WT generators. The solution used in the current study for the DBR-Boost SG WT unity power factor problem is the improvement of the system current rating.

To analyze the unity power factor problem more accurately, direct and quadrature axes equivalent to the circuit of the EESG detailed in Table 1 are considered, as shown in Figure 5 [22]. Using this equivalent circuit for DBR-Boost SG WT in the rated loading condition and assuming that DBR loading of the EESG acts as resistance $(r)$ at the fundamental frequency, the steadystate operation of this WT generator is described by Eq. (2):

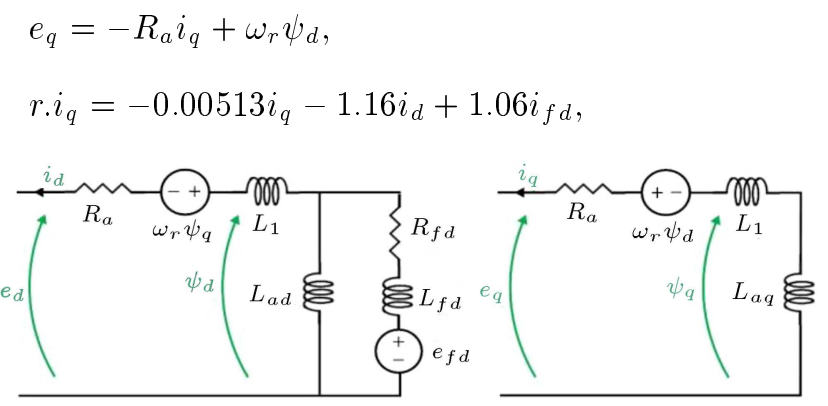

Figure 5. Electrically Excited Synchronous Generator (EESG) direct and quadrature axes equivalent circuit.

$$
\begin{gathered}
e_{d}=-R_{a} i_{d}-\omega_{r} \psi_{q} \quad \Rightarrow r . i_{d}=-0.00513 i_{d}+0.47 i_{q} \\
P=e_{d} i_{d}+e_{q} i_{q} \quad r . i_{d}^{2}+r . i_{q}^{2}=\frac{2.5 \mathrm{MW}}{3.4 \mathrm{MVA}} .
\end{gathered}
$$

It is noted that the EESG excitation current in the DBR-Boost SG WT is adjusted to more than 1 p.u $\left(i_{f d}=1.08 \mathrm{p} . \mathrm{u}\right)$ to help its boost converter operation in low wind speed condition. Thus, solving Eq. (2) results in the following values for the generator terminal current and voltage:

$$
\begin{aligned}
i_{d} & =0.34 \text { p.u, } i_{q}=0.8 \text { p.u } \rightarrow I_{t}=0.88 \text { p.u, } \\
V_{t} & =0.82 \text { p.u. }
\end{aligned}
$$

To analyze the same issue for the ECSG WT, the equivalent circuit of Figure 5 is considered again with terminal resistance $(r)$. In addition, it is supposed that under full load conditions, the generator excitation current is raised by $10 \%\left(i_{f d}=1.18\right.$ p.u $)$ compared to the DBR-Boost SG WT. Then, solving Eq. (2) results in:

$$
\begin{aligned}
i_{d} & =0.184 \text { p.u, } \quad i_{q}=0.635 \text { p.u } \rightarrow I_{t}=0.66 \text { p.u, } \\
V_{t} & =1.05 \text { p.u. }
\end{aligned}
$$

As is seen, this ECSG WT requires 25\% lower current than DBR-Boost SG WT to deliver the rated active power. In the case of DBR-Boost SG, the unity power factor problem is alleviated by raising the generator current rating, although the generator terminal voltage drop persists. On the other hand, ECSG-based WTs compensate the generator terminal voltage drop under heavy load conditions by raising the generator excitation and eliminate the problems associated with unity power factor operation of DBR equipped WT generators, with no need for the EESG redesign or current rating improvement of the generator and the converter.

Finally, VSC-based SG WTs do not suffer from the unity power factor problem, since reactive power injection capability provided by the VSC permits recovering the $\mathrm{SG}$ terminal voltage in the full load operation [18,21]. For example, for the VSC SG WT of the current study, assuming the rated no-load voltage and lagging power factor of 0.96 at the generator terminal in the full-load condition, the following can be deduced from equivalent circuit given in Figure 5:

$$
\begin{aligned}
& i_{d}=0.04 \text { p.u, } \quad i_{q}=0.72 \text { p.u } \rightarrow I_{t}=0.72 \text { p.u } \\
& V_{t}=1.01 \text { p.u }
\end{aligned}
$$

It is observed that this WT delivers its rated power with a current magnitude slightly higher than the ECSG WT, without terminal voltage drop. 


\subsection{WT converter unit reliability}

Overall, active switching devices (like IGBTs) along with their control circuits have much lower reliability than passive ones (diodes). Thus, the smaller the number of active switching devices in a converter, the better its reliability $[8,23,24]$. To ensure a deeper investigation into the converter reliability of the three WTs under study, an estimation of their reliability is presented here. The well-known failure rate approach is employed for this purpose and the study assumes sheltered offshore condition for WTs converter unit. Ref. [25] presented a detailed study of failure rate prediction of electronic circuit components, regarding different factors such as environmental situation, operating temperature, loading patterns, and so on. Since converter units of all the three WTs considered consist of two identical modules, reliability evaluation of one converter module of each WT will be enough to make the comparison. Accordingly, component failure rates $(\lambda)$ of one 3-phase converter module of the VSC SG WT are estimated in Table $2[21,25]$. Using these failure rates and considering that failure of each component will result in loss of converter functionality, the overall failure rate of a VSC module is calculated as follows:

$$
\lambda_{T}=\lambda_{L F}+6 \cdot \lambda_{I G B T}+\lambda_{C}+\lambda_{C S},
$$

Thus, a converter module of the VSC SG WT has a total failure rate of $\lambda_{T}=20.53 \times 10^{-6}$, and its Mean Time to Failure (MTTF) is:

$$
\operatorname{MTTF}=\frac{1}{\lambda_{T}}=48,700(h) .
$$

Similarly, the component failure rate of the ECSG WT 3-phase converter module is estimated, as shown in Table 3 [25], and its overall failure rate is $\lambda_{T}=$ $4.075 \times 10^{-6}$, resulting in MTTF of $245,400(\mathrm{~h})$ for this WT.

Finally, the failure rate of a 3-phase converter module for the DBR-Boost SG WT is estimated as shown in Table 4 [21,25], predicting a total failure rate of $\lambda_{T}=10.133 \times 10^{-6}$ and MTTF of $98,700(\mathrm{~h})$ for this converter.

As shown in the results, the ECSG WT has the most reliable converter unit which is twice more reliable than the DBR-Boost SG WT, and the DBR-Boost SG WT converter is of second grade, with twice more reliability than the VSC SG WT converter unit. WTs with a higher reliability converter are very advantageous,

\begin{tabular}{|c|c|c|}
\hline & Component & $\lambda(1 / h)$ \\
\hline 1 & 3-phase line filter inductor, $\lambda_{L f}$ & $1.065 \times 10^{-6}$ \\
\hline 2 & Each IGBT unit of VSC along with freewheeling diode (6 units), $\lambda_{I G B T}$ & $1.944 \times 10^{-6}$ \\
\hline 3 & DC link capacitor, $\lambda_{C}$ & $2.8 \times 10^{-6}$ \\
\hline 4 & VSC control system and the IGBTs gate drives, $\lambda_{C S}$ & $5 \times 10^{-6}$ \\
\hline \multicolumn{2}{|r|}{ Overall failure rate of converter, $\lambda_{T}$} & $20.53 \times 10^{-6}$ \\
\hline
\end{tabular}

Table 2. VSC SG WT 3-phase converter module failure rate.

Table 3. Excitation Controlled Synchronous Generator-based Wind Turbine (ECSG WT) 3-phase converter module failure rate.

\begin{tabular}{ccc}
\hline & Component & $\boldsymbol{\lambda}(\mathbf{1} / \mathbf{h})$ \\
\hline 1 & Each diode of DBR (6 diodes), $\lambda_{\text {Diode }}$ & $0.07 \times 10^{-6}$ \\
2 & DC link capacitor, $\lambda_{C}$ & $2.8 \times 10^{-6}$ \\
3 & DC current smoothing inductor, $\lambda_{L}$ & $0.855 \times 10^{-6}$ \\
\hline \multicolumn{2}{l}{ Overall failure rate of converter, $\boldsymbol{\lambda}_{\boldsymbol{T}}$} & $\mathbf{4 . 0 7 5} \times \mathbf{1 0}^{-\mathbf{6}}$ \\
\hline
\end{tabular}

\begin{tabular}{|c|c|c|}
\hline & Component & $\lambda(1 / h)$ \\
\hline 1 & Each diode of DBR (6 diodes), $\lambda_{\text {Diode }}$ & $0.07 \times 10^{-6}$ \\
\hline 2 & DC current smoothing inductor, $\lambda_{L}$ & $0.855 \times 10^{-6}$ \\
\hline 3 & IGBT of Boost converter, $\lambda_{I G B T}$ & $1.944 \times 10^{-6}$ \\
\hline 4 & Fast diode of Boost converter, $\lambda_{F D}$ & $1.614 \times 10^{-6}$ \\
\hline 5 & DC link capacitor, $\lambda_{C}$ & $2.8 \times 10^{-6}$ \\
\hline \multirow[t]{2}{*}{6} & Boost converter control system and its IGBT gate drive, $\lambda_{C S}$ & $2.5 \times 10^{-6}$ \\
\hline & Overall failure rate of converter, $\lambda_{T}$ & $10.133 \times 10^{-6}$ \\
\hline
\end{tabular}

Table 4. DBR-boost SG WT 3-phase converter module failure rate. 
especially for offshore applications, since converter failure is one of the major faults and WTs maintenance in offshore is expensive and more importantly, weatherdependent, which can result in weeks of lost electricity generation for the faulty offshore WT $[3,4,8,13]$.

\subsection{Response time to control signal change}

Another unique capability of ECSG WT in comparison to other WT schemes is that its controlling parameter (generator excitation current) simultaneously manages both of the influencing factors in the generator output active power, i.e., generator terminal voltage and current. More clearly, a change in the generator excitation voltage rapidly results in variation of the generator excitation current and its e.m.f and subsequently, its terminal voltage and current magnitudes will change since both of them are functions of the generator e.m.f. In contrast, in a VSC SG WT, a step change in the WT control signal (AC current reference of VSC) causes a rapid change in the stator current magnitude; however, since the excitation current is constant, generator e.m.f varies only in accordance with the generator speed, which is a slow process due to the turbine inertia. The same situation holds for DBR-Boost SG WT since the WT control signal is the boost converter input current magnitude, which manages the generator terminal current magnitude indirectly through DBR. The generator e.m.f is again a function of its speed only; thus, the WT control signal has a partial influence on the generator output active power. As a result, ECSG WT responds faster to its control signal change than the other two WT schemes under study.

To demonstrate the above conclusion, the three WTs specified in Section 2 are simulated in varying input wind speed conditions, and their dynamic responses are compared. In these simulations, the WT control loops are deactivated to avoid the impact of their dynamics on the WTs overall response time. Instead, at each wind speed and according to the relevant lookup tables, WT control signals are set to the final value that the MPPT algorithm would choose if the WTs control loops were active. Under this circumstance, the three WTs are simulated for a 30second run period. During this period, the wind speed changes from $12 \mathrm{~m} / \mathrm{s}$ initial value to $8 \mathrm{~m} / \mathrm{s}$ at the 10 th second of run and back to the initial value at the 20th second. The resulting output powers of the WTs are shown in Figure 6. As illustrated by the results, the ECSG WT offers an inherently dynamic response faster to the input wind speed change than the VSC SG and DBR-Boost SG WTs. This is the same result that was predicted theoretically.

\subsection{Low Voltage Ride Through (LVRT)}

Grid codes for different countries require that the WTs remain connected to the grid during and after severe

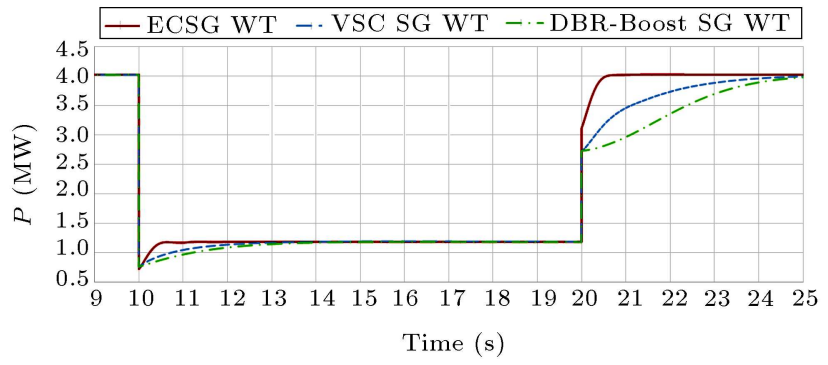

Figure 6. Dynamic response comparison for the three Wind Turbine (WT) schemes.

grid disturbances. More clearly, in the fault period, WTs must withstand voltage dips of up to a certain percentage of the nominal voltage within the specified time duration to ensure fast recovery of active power after fault clearance. Besides, WTs must provide reactive power for the grid to support its voltage during the fault [26-28].

In the WTs with a full rated power converter, the converter decouples the generator from the grid. Thus, the generator has nothing to do with reactive power requirements of WT output and it is the grid side converter that is responsible for these requirements [2830]. For VSC SG, DBR-Boost SG and ECSG WTs are considered in this study, since the grid side converters have been eliminated due to their similar structure, it can be deduced that reactive power requirements of the three WTs will be fulfilled by employment of a proper grid side converter for them.

To investigate the other aspects of LVRT requirements for the three WTs under study, it is noted that in the conventional VSC SG WT, the generator-side converter controls the generator speed according to the MPPT algorithm, while the grid-side converter is responsible for DC-link voltage regulation and reactive power injection to the grid $[27,29]$. For this WT, then, when the grid experiences a fault, the grid side converter current rises to maintain active power delivery to the grid. If the grid voltage dip is severe, the grid side converter current will reach its upper limit and active power injection to the grid will be curtailed. On the other hand, the generator side converter of the WT does not sense the voltage dip in the grid and continues to absorb active power. In this situation, due to the unbalance between input and output powers, the surplus power charges the DC-link capacitor of the back-to-back converter, causing voltage stress for both of VSCs and DC-link capacitors, which can result in the WT trip [26-30]. To remedy this problem and meet the LVRT requirements, two foremost methods have been proposed in the literature for VSC SG-based WTs. The first method is based on external device employment on the converter's DC-link to dissipate or store surplus power in the event of grid fault. Different energy storage systems and braking choppers have been 
employed as external devices of this method. This method can be applied for all WTs equipped with full rated power converter and a DC-link, regardless of the specific design of the converter, and is, therefore, applicable to all the three WTs of the current study. The second method is based on the WTs controller system modification such that LVRT requirements are fulfilled. This method is more cost-effective and relies on the capabilities of the WT structure. Therefore, effectiveness of this method must be discussed individually for each SG-based WT $[26,28,29]$. In the VSC SG WT, the WT control algorithm is redesigned such that the generator side VSC reduces its power absorption considerably as soon as the grid fault is detected. This remedy allows the WT surplus power to be stored in the inertia of the turbine-generator rotating parts (with increased rotational speed) immediately after fault occurrence. In the following, the slower pitch angle control of WT limits the WT captured power by changing the blades' pitch angle. This strategy solves DC-link over voltage problem and prevents excessive rise of the WT rotational speed, permitting the VSC SG WT to remain grid connected during the fault. Besides, in this condition, the grid side converter of the WT is able to allocate more capacity to reactive power generation due to the limited active power flow of WT during the fault [27-30]. The same solution can be employed for ECSG-based WT through immediate reduction of the generator excitation voltage following the grid fault detection. Moreover, faster dynamic response of ECSG WT helps implement this solution more effectively and with less voltage transient on its DC link. In contrast, in the case of DBR-Boost SG WT, slower dynamic response of WT than the VSC SG WT (according to Figure 6) might cause more severe overvoltage on the WT's DC link before the pitch angle controller regulates the turbine absorbed power.

\section{Economic assessments}

To make a cost-related comparison between the three WT schemes introduced in Section 2, it is considered that these WTs employ the same mechanical parts with identical costs. Thus, for the purpose of cost comparison, it is enough to estimate the costs of the parts that are different among the three WTs, i.e., terminal power converters. It is recalled that although the identical generator design is assumed for the three WT schemes, due to the unity power factor problem of DBR-Boost SG WT scheme, it requires a higher current capacity SG than the VSC SG and ECSG WTs, resulting in higher generator costs for this WT scheme.

For the purpose of power converter cost estimation, the VSC SG WT scheme in Figure 1 is considered again. In this figure, each 3-phase converter module comprises six IGBTs, a DC link capacitor, and three inductors as generator line filters. Technical data associated with these components and the procedure used for their selection were described in Section 2.1. The price list of these components is given in Table 5 [31,32]. As seen earlier, one 3-phase converter module of the VSC SG WT costs about $\$ 14,280$ and the total price of this WT converter unit is estimated to be about $\$ 28,560$.

The second type to be considered is ECSG WT shown in Figure 2. One 3-phase converter module of this WT consists of a DBR (six diodes), a DC link current smoothing inductor, and a DC link capacitor. Technical data of these components were discussed in Section 2.2. Cost estimation of each 3-phase converter module is given in Table $6[31,32]$. As the results show, the converter unit of the proposed ECSG WT, consisting of two identical 3-phase modules, costs about $2 \times \$ 7,891=\$ 15,782$.

Finally, the DBR-Boost SG WT of Figure 3 is considered. A 3-phase converter module of this WT consists of a DBR and a DC link boost converter. De-

Table 5. VSC SG WT 3-phase converter module cost details.

\begin{tabular}{cccc}
\hline & Component & Quantity & Price (\$) \\
\hline 1 & 3-phase line filter inductor of 15 mH-400 A & 1 & $1 \times 2,740$ \\
2 & $6.5 \mathrm{kV}-500 \mathrm{~A}$ IGBT with freewheeling diode & 6 & $6 \times 1,680$ \\
3 & DC link capacitor of $1000 \mu \mathrm{F}-7.0 \mathrm{kV}$ & 1 & $1 \times 1,460$ \\
\hline \multicolumn{3}{c}{ Total price } & 14,280 \\
\hline
\end{tabular}

Table 6. Excitation Controlled Synchronous Generator-based Wind Turbine (ECSG WT) WT 3-phase converter module cost details.

\begin{tabular}{cccc}
\hline & Component & Quantity & Price (\$) \\
\hline 1 & $6.5 \mathrm{kV}-770$ A diode & 6 & $6 \times 501$ \\
2 & DC current smoothing inductor of $75 \mathrm{mH}-500 \mathrm{~A}$ & 1 & $1 \times 3,425$ \\
3 & DC link capacitor of $1000 \mu \mathrm{F}-7.0 \mathrm{kV}$ & 1 & $1 \times 1,460$ \\
\hline \multicolumn{2}{c}{ Total price } & & 7,891 \\
\hline
\end{tabular}


Table 7. DBR-boost SG WT 3-phase converter module cost details.

\begin{tabular}{cccc}
\hline & Component & Quantity & Price (\$) \\
\hline 1 & $6.5 \mathrm{kV}-770$ A diode & 6 & $6 \times 501$ \\
2 & DC current smoothing inductor of $75 \mathrm{mH}-700 \mathrm{~A}$ & 1 & $1 \times 4,150$ \\
3 & $6.5 \mathrm{kV}-750$ A IGBT of boost converter & 1 & $1 \times 2,177$ \\
4 & $6.5 \mathrm{kV}-750$ A fast recovery diode of boost converter & 1 & $1 \times 1,140$ \\
5 & DC link capacitor of $1000 \mu \mathrm{F}-7.0 \mathrm{kV}$ & 1 & $1 \times 1,460$ \\
\hline \multicolumn{2}{c}{ Total price } & & 11,933 \\
\hline
\end{tabular}

tails of these components were discussed in Section 2.3. Cost estimation for such a 3 -phase converter module is given in Table $7[31,32]$. As is seen, the total price of the DBR-Boost SG WT converter unit, consisting of two 3 -phase modules, is estimated to be about $\$ 23,866$.

As the results suggest, VSC SG WT has the most expensive converter with the total price of $\$ 28,560$ since it employs twelve costly IGBTs. DBR-Boost SG WT has the second most expensive converter. Even though it costs $16.4 \%$ lower than the VSC SG WT converter, employment of two boost converters in its DC links has limited its cost reduction potential. Finally, the ECSG WT converter is the most economic scheme among the three WTs with cost saving of $44.7 \%$ with respect to VSC SG WT and $33.9 \%$ with respect to DBR-Boost SG WT. This is a valuable achievement for an SG-based WT since the expensive converter unit has remained one of the main drawbacks of such WTs for years $[1,8,18,21]$.

A similar economic comparison between backto-back VSC-VSC SG and DBR-VSC SG WTs was presented in [21] regarding $\mathrm{AC}$ grid connection. The results achieved in [21] indicate that for the AC grid connection, replacement of SG-side VSC with DBR will lead to a $23.5 \%$ reduction in the overall price of the WT converter unit. In order to consider the unity power factor problem for DBR-VSC SG WT, its components were redesigned in [21] and the associated costs slightly increased. Upon adjusting the results of [21] for equivalent DC grid connection WTs, it is observed that the converter unit of DBR SG WT scheme costs $42 \%$ less than the VSC SG configuration. This estimation is reasonably close to the results of the current study. It is recalled that DBR SG WT has a similar electrical layout with ECSG-based WT, except that the ECSG WT converter and generator have lower current ratings since this WT does not suffer from unity power factor problem.

\section{Efficiency of the three WT schemes}

In this section, efficiencies of the ECSG, DBR-Boost SG, and VSC SG WTs are compared. This comparison only includes electrical parts of the three WTs since their mechanical parts are the same with identical losses. For the purpose of the current study, loss calculation for WT electrical parts is divided into two steps. First, generator loss of the three WTs is calculated. Then, their converter losses are estimated and the overall efficiencies of the three WTs are obtained. Note that simulation results of the three WTs at several different loadings provide the required data for this loss calculation. As mentioned earlier, generator loss of the three WTs is studied first. EESG losses consist of the core loss and the stator ohmic loss (rotor ohmic loss is assumed negligible). To calculate the core loss of each 3-phase module, the following two relations are considered [21,33]:

$$
\begin{aligned}
& P_{\text {Hyst. }} \sim B^{2} \cdot f, \\
& P_{\text {Eddy Cur. }} \sim B^{2} \cdot f^{2},
\end{aligned}
$$

where hysteresis and eddy current core losses are related to the core flux density $(B)$ and stator frequency $(f)$. On the other hand, $B$ is proportional to $\frac{\text { Statore.m.f }}{f}$. Then, by using the values of hysteresis and eddy current losses in the rated condition, components of the generator core loss associated with the fundamental and harmonic magnetic fields can be measured in different loading conditions [21]:

$$
\begin{aligned}
& P_{\text {Hyst. }-h}=P_{\text {Hyst. }-R}\left(\frac{\text { e.m. } f_{h}}{\text { e.m. } f_{R}}\right)^{2}\left(\frac{f_{R}}{f_{h}}\right)_{\text {Hyst. }-h}, \\
& P_{\text {EddyCur. }-h}=P_{\text {EddyCur. }-R}\left(\frac{\text { e.m. } f_{h}}{\text { e.m. } f_{R}}\right)_{\text {EddyCur. }-h}^{2},
\end{aligned}
$$

\begin{tabular}{|c|c|}
\hline$P_{\text {Hyst. }-h}$ & $\begin{array}{l}\text { Hysteresis loss of harmonic } h \text { magnetic } \\
\text { field }\end{array}$ \\
\hline$P_{E d d y C u r .-h}$ & $\begin{array}{l}\text { Eddy current loss of harmonic } h \\
\text { magnetic field }\end{array}$ \\
\hline$P_{\text {Hyst. }-R}$ & Rated hysteresis loss \\
\hline$P_{E d d y C u r .-R}$ & Rated eddy current loss \\
\hline e.m. $f_{h}$ & $\begin{array}{l}\text { Harmonic component of stator phase } \\
\text { e.m.f }\end{array}$ \\
\hline$e . m \cdot f_{R}$ & Rated stator phase e.m.f \\
\hline$f_{h}$ & Harmonic $h$ frequency \\
\hline$f_{R}$ & Rated stator frequency \\
\hline
\end{tabular}

where: 
Thus, using the results of harmonic analysis provided by WTs simulation, the EESG main and harmonic core losses at different loadings can be calculated for the three WTs. Note that in ECSG and DBR-Boost SG WTs, stator e.m.f and phase current harmonic components are obtained through Fourier analysis of their simulated wave forms.

The other source of loss for WTs generator is the ohmic loss of stator windings. The equation of this loss for each EESG 3-phase stator module can be written as follows [33]:

$$
P_{C u}=3 R_{S} \cdot I_{r . m . s}^{2},
$$

where:

$$
\begin{array}{ll}
R_{s} & \text { EESG stator phase resistance } \\
I_{\text {r.m.s }} & \text { Stator r.m.s phase current }
\end{array}
$$

Finally, the total generator loss of VSC SG WT, considering two 3-phase stator modules, is as follows:

$$
P_{S G \text { Loss }}=2 \times\left(P_{\text {Hyst. }-1}+P_{\text {EddyCur.-1 }}+P_{C u}\right),
$$

and total generator loss of the other two WTs is:

$$
\begin{aligned}
P_{S G L o s s} & =2 \times\left(\sum_{h} P_{\text {Hyst. }-h}+\sum_{h} P_{\text {EddyCur. }-h}\right. \\
& \left.+P_{C u}\right) .
\end{aligned}
$$

In Eq. (10), only the core loss components corresponding to the fundamental frequency are considered since harmonic contents of the generator air gap flux and terminal voltage caused by pulse-width modulated VSC are negligible. Following the calculation of the generator loss for the three WTs, generators' efficiencies are presented in Figure 7.

For loss calculation of the WTs converter units, one 6-pulse DBR loss is studied first. Because of the low switching rate at the SG stator frequency for DBR leg diodes, their switching loss is negligible and the diodes conduction loss component is the main source of loss for DBRs. Considering that two diodes are

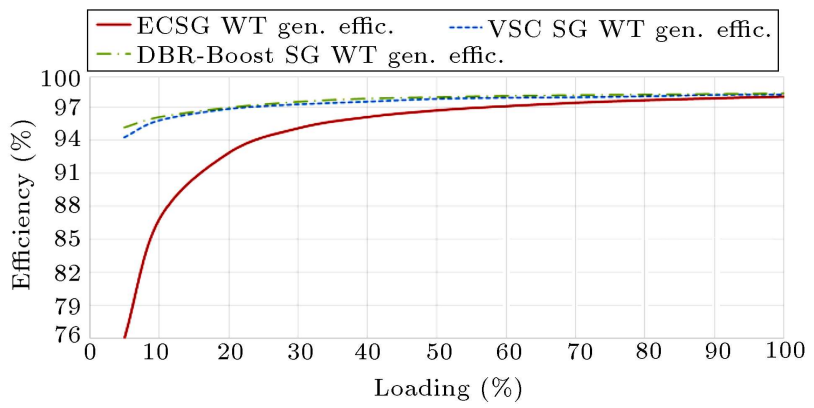

Figure 7. Efficiency comparison of the 3 WT generators at different loadings. conducting simultaneously at each moment of 3-phase DBR operation, DBR conduction loss equation can be written as $[21,34]$ :

$$
P_{D B R} \approx P_{\text {DiodeCond. }}=2 \times\left(V_{D 0} \cdot I_{D C}+r_{D} \cdot I_{D C}^{2}\right),
$$

where:

$V_{D 0} \quad$ Leg diodes forward bias voltage drop at small currents

$r_{D} \quad$ Leg diodes forward bias resistance

$I_{D C} \quad$ DC link current of 6-pulse DBR

The next converter to be considered is the $\mathrm{DC} / \mathrm{DC}$ boost converter employed in the DBR-Boost SG WT. For this converter, conduction and switching losses are equally important and both should be considered. In the switching period of $T$ for the boost converter given in Figure 3, the IGBT conducts in D.T seconds ( $D$ is duty cycle of the boost converter) and the diode conducts in the remaining $(1-D) . T$ seconds. Thus, conduction loss equations for switching devices of this converter can be written as:

$$
\begin{aligned}
& P_{I G B T C o n d .}=\left(V_{C E 0} \cdot I_{L}+r_{C E} \cdot I_{L}^{2}\right) \cdot D, \\
& P_{\text {DiodeCond. }}=\left(V_{D 0} \cdot I_{L}+r_{D} \cdot I_{L}^{2}\right) \cdot(1-D),
\end{aligned}
$$

where:

$V_{C E 0} \quad$ IGBT on state collector emitter voltage drop at small currents

$r_{C E} \quad$ IGBT on state collector emitter resistance

$I_{L} \quad$ Boost converter inductance current

$V_{D 0} \quad$ Diode on state voltage drop at small currents

$r_{D} \quad$ Diode on state resistance

For the switching loss calculation of the boost converter, it is noted that the nominal switching loss given in the data sheet of a switching device is at rated voltage and current condition. In practical applications, they change proportional to the device operating voltage and current. Therefore, switching loss equation of the boost converter IGBT can be written as follows:

$$
P_{I G B T S w}=f_{S w} \cdot\left(E_{o n}+E_{o f f}\right) \cdot\left(\frac{I_{L}}{I_{R}}\right) \cdot\left(\frac{V_{o u t}}{V_{R}}\right),
$$

where:

$f_{S w} \quad$ Switching frequency of Boost converter

$E_{\text {on }} \quad$ Turn on energy losses of IGBT in nominal conditions

$E_{\text {off }} \quad$ Turn off energy losses of IGBT in nominal conditions

$V_{\text {out }} \quad$ Boost converter output voltage

$I_{R} \quad$ IGBT rated current

$V_{R} \quad$ IGBT rated voltage 
According to the studies [21,34], for fast recovery diodes, turn-on energy losses are negligible; thus, it is enough to take into account only their reverse recovery energy loss $\left(E_{r e c}\right)$ in switching loss equation. Besides, fast recovery diodes' reverse recovery energy is not fully proportional to diode current. This dependence is considered to be below 50\% [21]; hence, the switching loss equation for the DC/DC boost converter diode is written as follows:

$$
P_{\text {DiodeSw }}=f_{S w} \cdot E_{R e c}\left(\frac{0.45 I_{L}}{I_{R}}+0.55\right) \cdot\left(\frac{V_{\text {out }}}{V_{R}}\right)_{(16)}
$$

where:

$E_{\text {Rec }} \quad$ Nominal reverse recovery energy loss of diode

$I_{R} \quad$ Diode rated current

$V_{R} \quad$ Diode rated voltage

and the total loss equation for boost converter is:

$$
\begin{aligned}
P_{\text {BoostLoss }}= & P_{I G B T C o n d .}+P_{\text {DiodeCond. }}+P_{I G B T S w} \\
& +P_{\text {Diode } S w} .
\end{aligned}
$$

Finally, loss calculation of a 3-phase VSC module employed in VSC SG WT is considered. In this converter, the switching devices have two loss components including conduction and switching losses. According to studies [21] and [34], the appropriate conduction loss equation for IGBTs of a 3-phase VSC is written as follows:

$$
\begin{array}{r}
P_{I G B T C \text { ond } .}=\frac{1}{2}\left(V_{C E 0 \cdot} \cdot \frac{I}{\pi}+r_{C E} \cdot \frac{I^{2}}{4}\right) \\
+m \cdot \cos \theta \cdot\left(V_{C E 0} \cdot \frac{I}{8}+\frac{1}{3 \pi} r_{C E . I}^{2}\right),
\end{array}
$$

where:

$\theta \quad$ AC side phase angle

I $\quad$ VSC AC side current magnitude (peak value)

$m \quad$ Modulation index of VSC (equal to peak value of line-to-line voltage divided by DC link voltage)

A similar equation can be deduced for freewheeling diodes of this converter, with a slight difference that these diodes conduct when the VSC IGBTs are turned off $[21,34]$ :

$$
\begin{array}{r}
\text { Piode Cond. }_{\text {Did }}=\frac{1}{2}\left(V_{D 0} \cdot \frac{I}{\pi}+r_{D} \cdot \frac{I^{2}}{4}\right) \\
-m \cdot \cos \theta \cdot\left(V_{D 0} \cdot \frac{I}{8}+\frac{1}{3 \pi} r_{D} \cdot I^{2}\right) .
\end{array}
$$

On the other hand, the switching loss equation of 3 -phase VSC IGBTs is [21,34]:

$$
\begin{aligned}
P_{I G B T S w}= & \frac{1}{\pi} f_{S w} \cdot\left(E_{o n}+E_{o f f}\right) \cdot\left(I / I_{R}\right) \\
& \cdot\left(V_{D C} / V_{R}\right)
\end{aligned}
$$

where $f_{s w}$ is switching frequency of the VSC. Accordingly, the corresponding switching loss equation for the VSC freewheeling diodes is [21]:

$$
\begin{aligned}
P_{\text {Diode } S w}= & \frac{1}{\pi} f_{S w} \cdot E_{R e c}\left(0.45 I / I_{R}+0.55\right) \\
& \cdot\left(V_{D C} / V_{R}\right)
\end{aligned}
$$

and VSC total loss equation is written similar to Eq. (17).

Data derived from the switching devices of the WT converter units that are required for measuring their loss are given in Tables 8 and 9 [20].

The three WTs converter loss calculations are performed accordingly and the results are presented in Figure 8.

Upon combining the generator and converter losses of these WTs, their overall efficiencies are calculated and illustrated in Figure 9. It is worth noting that the obtained VSC SG and DBR-Boost SG WTs results here conform to the efficiency results given in [21] for back-to-back SG and DBR-Boost-VSC SG WTs, confirming the accuracy of the calculations.

Based on comparing the new ECSG-based WT efficiency with those of the other two WTs in Figure 9, it is seen the ECSG WT has higher efficiency than the VSC SG WT at loadings greater than $35 \%$ and it outperforms DBR-Boost SG WT for above $60 \%$ loadings. The main drawback of ECSG WT is its low load (about $5 \sim 15 \%$ loadings) efficiency, which is considerably smaller than the other two WTs. The reason for this difference is further studied in the rest of this section to determine a solution to the problem. According to the results of Figures 7 and 8, the ECSG

Table 8. Wind Turbines (WTs) converter unit IGBT data.

\begin{tabular}{cccccccc}
\hline WT type & Converter & $\boldsymbol{V}_{\boldsymbol{C E 0}}$ & $\boldsymbol{r}_{\boldsymbol{C E}}$ & $\boldsymbol{E}_{\text {on }}$ & $\boldsymbol{E}_{\text {off }}$ & $\boldsymbol{V}_{\boldsymbol{R}}$ & $\boldsymbol{I}_{\boldsymbol{R}}$ \\
\hline DBR-Boost SG & Boost & $1.4 \mathrm{~V}$ & $1.9 \mathrm{~m} \Omega$ & $4.2 \mathrm{~J}$ & $3.6 \mathrm{~J}$ & $6.5 \mathrm{kV}$ & $750 \mathrm{~A}$ \\
VSC SG & VSC & $1.3 \mathrm{~V}$ & $2.8 \mathrm{~m} \Omega$ & $2.8 \mathrm{~J}$ & $2.4 \mathrm{~J}$ & $6.5 \mathrm{kV}$ & $500 \mathrm{~A}$ \\
\hline
\end{tabular}


Table 9. Wind Turbines (WTs) converter unit diode data.

\begin{tabular}{ccccccc}
\hline WT type & Converter & $\boldsymbol{V}_{\boldsymbol{D} \mathbf{0}}$ & $\boldsymbol{r}_{\boldsymbol{D}}$ & $\boldsymbol{E}_{\boldsymbol{r e c}}$ & $\boldsymbol{V}_{\boldsymbol{R}}$ & $\boldsymbol{I}_{\boldsymbol{R}}$ \\
\hline ECSG & DBR & $0.84 \mathrm{~V}$ & $0.87 \mathrm{~m} \Omega$ & - & $6.5 \mathrm{kV}$ & $770 \mathrm{~A}$ \\
DBR-Boost SG & DBR & $0.84 \mathrm{~V}$ & $0.87 \mathrm{~m} \Omega$ & - & $6.5 \mathrm{kV}$ & $770 \mathrm{~A}$ \\
& Boost & $1.4 \mathrm{~V}$ & $1.6 \mathrm{~m} \Omega$ & $1.4 \mathrm{~J}$ & $6.5 \mathrm{kV}$ & $750 \mathrm{~A}$ \\
VSC SG & VSC & $1.3 \mathrm{~V}$ & $2.6 \mathrm{~m} \Omega$ & $0.93 \mathrm{~J}$ & $6.5 \mathrm{kV}$ & $500 \mathrm{~A}$ \\
\hline
\end{tabular}

WT high losses in low-load conditions result from high generator loss at lower loadings of this WT. On the other hand, since the DBR-Boost SG WT generator does not suffer the same problem, one concludes that it is not caused by harmonic currents or harmonic magnetic fields injected to the ECSG WT generator.

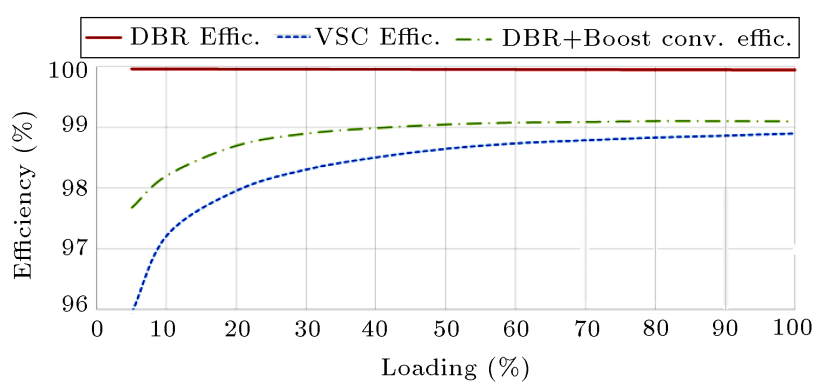

Figure 8. Efficiency comparison of three Wind Turbines (WTs) converters at different loadings.

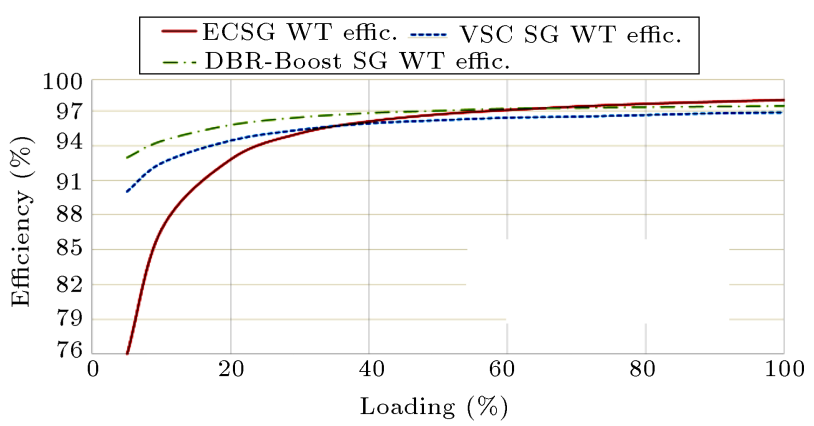

Figure 9. Overall efficiency comparison of the three Wind Turbines (WTs) at different loadings.
To gain a better insight, the generator 3-phase module loss is decomposed into its components at different loadings of ECSG WT in Figure 10. It is observed that the ohmic loss component increases rapidly as the WT loading increases, as expected. However, the growth rate of eddy current loss component of the generator core does not match the loading growth rate; even worse, the value of hysteresis loss component decreases as the WT loading increases. Thus, the ECSG WT high losses in low-load conditions originate from high generator core loss under this situation, because in low-load conditions, wind speed and WT rotational speed have dropped considerably in comparison to rated values. Consequently, the ECSG WT tries to increase the generator excitation current to overcome the reduced generator speed and induce the required stator e.m.f. This high excitation current increases the generator core loss and reduces its efficiency at light loadings.

To overcome the problem, flexible nature of DC grid WFs is employed. In a DC grid WF, grid voltage can be adjusted according to the required characteristics of the WF. Thus, in a DC grid WF composed of ECSG WT under study, local grid of the WTs could have a variable voltage magnitude instead of constant value of $10 \mathrm{kV}$. For example, suppose that WTs local grid employs $6 \mathrm{kV}$ voltage for the average WF loadings below $45 \%, 8 \mathrm{kV}$ for the average WF loadings between $45 \%$ and $85 \%$, and $10 \mathrm{kV}$ for the average farm loading greater than $85 \%$. In addition, the hysteresis band control method is employed for local grid voltage level selection to prevent repetitive

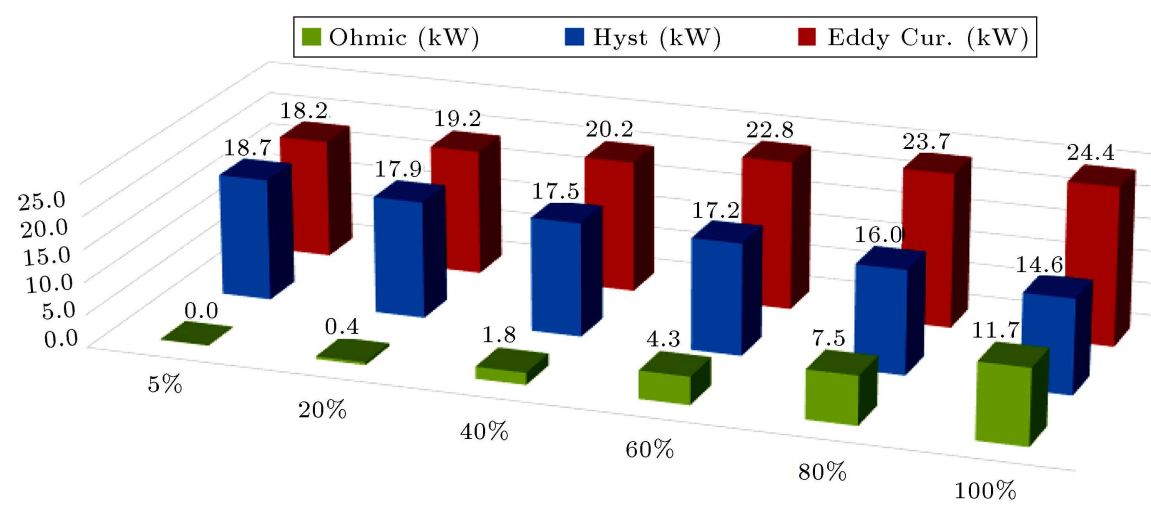

Figure 10. Excitation Controlled Synchronous Generator-based Wind Turbine (ECSG WT) generator loss decomposition at different loadings. 


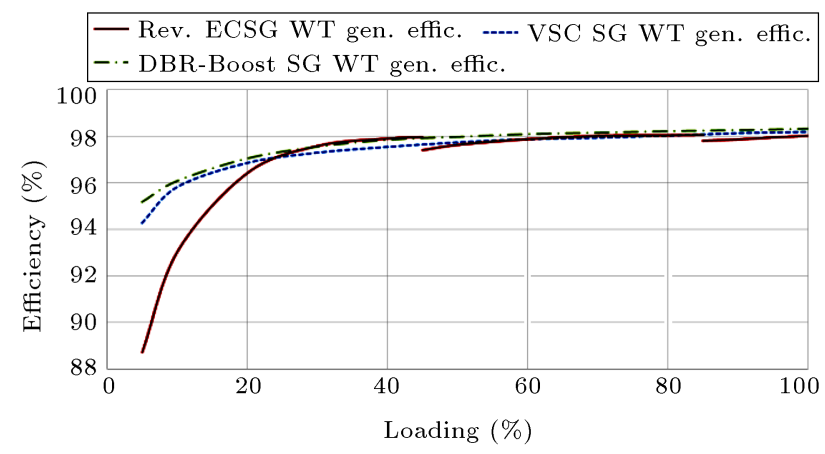

Figure 11. Efficiency comparison of variable DC grid voltage Excitation Controlled Synchronous Generator-based Wind Turbine (ECSG WT) generator with that of VSC SG WT and DBR-Boost SG WT.

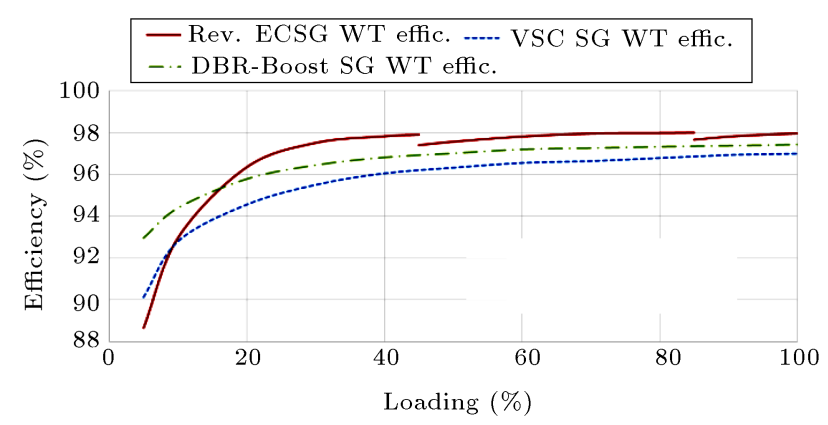

Figure 12. Overall efficiency comparison of variable Direct Current Direct Current (DC) grid voltage Excitation Controlled Synchronous Generator-based Wind Turbine (ECSG WT) with that of VSC SG WT and DBR-Boost SG WT.

voltage changes at marginal loadings. Employment of this three-level grid voltage control for the ECSG WT results in significant low load efficiency improvement, as shown in Figures 11 and 12 . Figure 11 depicts the generator efficiency for the three WTs employing modified grid voltage for ECSG WT and Figure 12 shows the overall WT efficiencies considering both their generator and converter units. As is seen, as the grid voltage level is changed from $6 \mathrm{kV}$ to $8 \mathrm{kV}$ at $45 \%$ loading or from $8 \mathrm{kV}$ to $10 \mathrm{kV}$ at $85 \%$ loading, the ECSG WT efficiency is improved significantly. These results demonstrate that the ECSG WT with threelevel grid voltage control yields overall efficiency in the range of the other two WTs for loadings below 15\%; beyond $20 \%$ loading, the ECSG WT delivers better efficiency than BDR-Boost SG WT with a margin of $0.5 \sim 1.0 \%$ and better efficiency than VSC SG WT with a margin of $1.0 \sim 2.0 \%$.

\section{ECSG based WF versus Siemens 2nd generation DC grid access offshore WF}

Recently, Siemens has introduced a new generation of its offshore WFs, named Siemens 2nd generation DC grid access offshore WF, which is based on offshore DC grid concept with major modifications applied to the farm structure and WTs grid connection. The result is a WF structure benefiting from advantages like $30 \%$ cost reduction, $65 \%$ topside weight reduction, $30 \%$ transmission capacity improvement, and $20 \%$ transmission loss reduction in comparison to the offshore WFs conventionally used $[19,35]$. This structure employs DBR modules as offshore side converters of the WF, which are more simple, robust, compact, and costeffective with low loss and maintenance cost. The 2nd-generation DC grid access offshore WF consists of several strings of WTs and each string has a number of SG-based WTs directly coupled to the string 3phase AC local grid through step-up transformers. Apparently, the string WT generators share a common frequency over the string local grid. Another side of the string ends up with a three-winding $\mathrm{Y} / \mathrm{Y} / \mathrm{D}$ transformer and two DBR modules that perform a 12pulse rectification task for the string. Figure 13 shows one WT string of such a WF schematically $[12,19,35]$. Note that the 12-pulse rectifier's DC side is series connected.

In the 2nd-generation DC grid access offshore WF, the WT strings are series connected on the DC side to build up a voltage level required for the farm HVDC transmission link, as shown in Figure 14. The onshore side VSC converter of the HVDC link connects the farm to the grid and adjusts the HVDC link voltage such that maximum power point of WF operation on average is met $[19,35]$.

It is evident that a single control parameter cannot be used for MPPT of all WTs in the 2nd-generation DC grid access offshore WF. Therefore, this WF is only

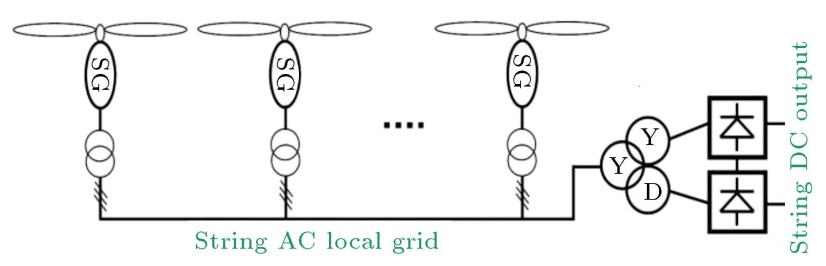

Figure 13. Single string structure of Siemens 2nd-generation Direct Current (DC) grid access offshore Wind Farm (WF).

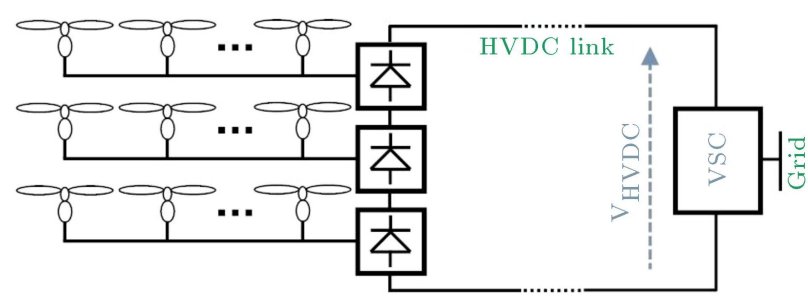

Figure 14. Overall structure of Siemens 2nd-generation Direct Current (DC) grid access offshore Wind Farm (WF). 
capable of tracking an average maximum power point of its WTs. In practice, different wind speeds at the farm WTs result in reduced extracted energy for the WF compared to the maximum value possible. This difference is intensified as the number of farm WTs and their wind speed difference increase [6,7]. Another disadvantage of this scheme appears in low wind speed conditions. In such a situation, rotational speed of WTs in a string and, accordingly, their terminal voltage are reduced significantly from rated values (It is recalled that in a constant excitation SG, stator e.m.f is proportional to the rotor rotational speed). Thus, DC output voltage of the string reduces considerably in comparison to full-load operation condition of the WF and consequently, the HVDC link voltage declines significantly. Then, if the DC voltage of the VSC is controlled in a range in which active power injection to the grid is facilitated even in low wind speed conditions, the HVDC link voltage varies widely from low-load to full-load operation and the VSC overall efficiency is reduced. On the other hand, limiting the HVDC link voltage variation to an acceptable level for high efficiency in the entire operation range results in loss of WF operation at low wind speeds. A similar problem for DBR-SG WT scheme necessitates the employment of a boost converter on its DC link and results in DBR-Boost SG WT scheme [8,21]. Finally, in the 2ndgeneration DC grid access offshore WF, voltage step up task from SGs terminal voltage level to the HVDC link voltage level is assigned to WT transformers along with series connection of DBR modules on DC side of the strings. Employment of step-up transformer at the stator terminal hinders use of DD SGs for such a WF structure, since the operating frequency of DD SG WTs is such low that makes the transformer too bulky and impractical. Therefore, the 2nd-generation DC grid access offshore WF is restricted to gear WTs with medium or high speed SGs.

In order to compare the performance of this scheme with that of an ECSG-based WF, consider a farm structure similar to that in Figure 14 in which each string consists of ECSG-based WTs connected parallel to a local DC line; thus, the string front-end rectifier is unnecessary. In this WF, similar to the Siemens 2nd-generation DC grid access offshore WF, HVDC link voltage is adjusted according to the average maximum power point of WTs, resulting in near MPP operation of each WT. Then, the fine tuning needed to reach the exact the maximum power point on each WT is applied by ECSG WT generator excitation, resulting in extraction of maximum possible power from the ECSG based WF, even if the farm wind profile is uneven. Another advantage of ECSG-based WF over Siemens 2nd-generation DC grid access offshore WF is that it does not suffer from the significant HVDC link voltage drop at low wind speeds since the ECSG
WTs excitation control provides boost capability over their terminal voltage and help preserve the HVDC link voltage at a more proper level.

\section{Conclusion}

A detailed comparison was made between the new Excitation Controlled Synchronous Generator based Wind Turbine (ECSGWT) scheme and two other Wind Turbine (WT) schemes, which are the main stream SG-based WTs. These WT schemes included VSCbased SG WT and diode bridge rectifier-based SG WT equipped with Direct Current (DC) link boost converter. Performances of these WTs were compared in terms of efficiency, cost, torque ripple, reliability, Low Voltage Ride Through (LVRT), and WTs response time to their control signal change. Also, variable grid voltage was employed for ECSG WT to improve its light load efficiency. Furthermore, another comparison was made between the recently introduced Siemens 2nd-generation DC grid access offshore Wind Farm (WF) and a WF with similar structure, but using ECSG-based WTs. The results of these comparisons show that the new WT scheme enjoys promising characteristics in economic, reliability, and efficiency terms.

\section{References}

1. Liserre, M., Cardenas, R., Molinas, M., et al. "Overview of multi-MW wind turbines and wind parks", Industrial Electronics, IEEE Trans. on, 58(4), pp. 1081-1095 (2011).

2. Anaya-Lara, O., O. Tande, J., Uhlen, K., et al. "Energy conversion systems for offshore wind turbines", In Offshore Wind Energy Technology, 1st Ed., pp. 13-34 John Wiley \& Sons (2018).

3. Al-Bahadly, I.H., Wind Turbine Generators and Drives, In Wind Turbines, Ed. 1st, pp. 463-639, InTech, Rijeka, Croatia (2011).

4. Zhang, Z., Chen, A., Matveev, A., et al. "Highpower generators for offshore wind turbines", Energy Procedia, 35, pp. 52-61 (2013).

5. Lloberas, J., Sumper, A., Sanmarti, M., et al. "A review of high temperature superconductors for offshore wind power synchronous generators", Renewable and Sustainable Energy Reviews, 38, pp. 404-414 (2014).

6. Prada, M., Lgualada, L., Corchero, C., et al. "Hybrid AC-DC offshore wind power plant topology", Power Systems, IEEE Transactions on., 30(4), pp. 1868-1876 (2015).

7. Madariaga, A., Martin, J.L., Zamora, I., et al. "Technological trends in electric topologies for offshore wind power plants", Renewable and Sustainable Energy Reviews, 24, pp. 32-44 (2013). 
8. Yaramasy, V., Wu, B., Sen, C., et al. "High-power wind energy conversion systems: State-of-the-art and emerging technologies", Proceedings of the IEEE, $\mathbf{1 0 3}(5)$, pp. $740-788(2015)$.

9. Polinder, H., Ferreira, J.A., Jensen, B., et al. "Trends in wind turbine generator systems", Emerging and Selected Topics in Power Electronics, IEEE Journal of, 1(3), pp. 174-185 (2013).

10. Ma, K., Tutelea, L., Boldea, I., et al. "Power electronic drives, controls, and electric generators for large wind turbines-an overview", Electric Power Components and Systems, 43(12), pp. 1406-1421 (2015).

11. Keysan, O. and Mueller, M.A. "A homopolar HTSG topology for large direct-drive wind turbines" Applied Superconductivity, IEEE Transactions on, 21(5), pp. 3523-3531 (2011).

12. Blaabjerg, F. and Ma, K. "Wind energy systems", Proceedings of the IEEE, 105(11), pp. 2116-2131 (2017).

13. Keysan, O., Radyjowski, P., Burchell, J., et al. "Towards more reliable and cost effective superconducting generators for wind turbines", Power Electronics, Machines and Drives (PEMD 2014), rth IET International Conference, Manchester, UK (2014).

14. Wu, B., Lang, Y., Zargari, N., et al. "Wind energy system configurations", In Power Conversion and Control of Wind Energy Systems, 1st Ed., pp. 153-170, John Wiley \& Sons, New Jersey, USA (2011).

15. Carrasco, J.M., Franquelo, L.G., Bialasiewicz, T., et al. "Power-electronic systems for the grid integration of renewable energy sources: A survey", IEEE Transactions on Industrial Electronics, 53(4), pp. 1002-1016 (2006).

16. Arántegui, R.L., Corsatea, T., and Suomalainen, K. "2012 JRC Wind Status Report", JRC Scientific and Policy Reports, Luxembourg, Office of the European Union, Institute for Energy and Transport (2013).

17. Shamsnia, A. and Parniani, M. "A new cost-effective wind farm structure with HVDC link preserving technical advantages of advanced offshore wind farms", (RE\&PQJ-11) Renewable Energy and Power Quality Journal, 11, pp. 640-644 (2013).

18. Mueller, M. and Polinder, H. "Electrical drive technology", In Electrical Drives for Direct Drive Renewable Energy Systems, 1st Ed., pp. 1-130, Woodhead Publishing, Cambridge, UK (2013).

19. https://www.siemens.com/press/pool/de/events/2015/ energymanagement/2015-10-dc-grid/presentation-dcgrid-e.pdf

20. https://www.infineon.com
21. Poore, R. and Lettenmaier, T. "Alternative design study Report: Wind PACT advanced wind turbine drive train designs study", (NREL) National Renewable Energy Laboratory, Colorado, USA (2003).

22. Prabha Kundur, "Synchronous machine theory and modelling", In Power System Stability and Control, Ed. 1st , pp. 45-105, McGraw-Hill Inc. (1994).

23. Wheeler, P., Clare, J., Lillo, L., et al. "A reliability comparison of a matrix converter and an 18-pulse rectifier for aerospace applications", 12th Power Electronics and Motion Control Conf., Portoroz, Slovenia, pp. 496-500 (2006).

24. Song, Y. and Wang, B. "Survey on reliability of power electronic systems", Power Electronics, IEEE Transactions on, 28(1), pp. 591-604 (2013).

25. Military Handbook: Reliability Prediction of Electronic Equipment, Department of Defense, Washington DC. Tech, Rep. MIL-HDBK-217F (1991).

26. Howlader, A.M. and Senjyu, T. "A comprehensive review of low voltage ride through capability strategies for the wind energy conversion systems", Renewable and Sustainable Energy Reviews, 56, pp. 643-658 (2016).

27. Alepuz, S., Calle, A., Monge, S., et al. "Use of stored energy in PMSG rotor inertia for low-voltage ridethrough in back-to-back NPC converter-based wind power systems", Industrial Electronics, IEEE Transactions on, 60(5), pp. 1787-1796 (2013).

28. Tsili, M. and Papathanassiou, S. "A review of grid code technical requirements for wind farms", IET Renewable Power Generation, 3(3), pp. 308-332 (2009).

29. Nasiri, M., Milimonfared, J., and Fathi, S.H. "A review of low-voltage ride-through enhancement methods for permanent magnet synchronous generator based windturbines", Renewable and Sustainable Energy Reviews, 47, pp. 399-415 (2015).

30. Nasiri, M. and Mohammadi, R. "Peak current limitation for grid side inverter by limited active power in PMSG-based wind turbines during different grid faults", Sustainable Energy, IEEE Transactions on, 8(1), pp. 3-12 (2017).

31. https://www.galco.com

32. http://www.reo.co.uk

33. Grauers, A. "Synchronous generator and frequency converter in wind turbine applications: system design and efficiency", Technical report, School of Electrical and Computer Engineering, Chalmers University of Technology (1994).

34. Applying IGBTs, ABB handbook, Application Note 5SYA 2053-04 https://library.e.abb.com/public/ab11 9704d4797bc283257cd3002ac5e0/Applying\%20IGB Ts_5SYA

35. http://www.ptd.siemens.de/CIGRE2016_B3110_2nd -generation_DC_GridAccess.pdf 


\section{Appendix}

\section{Mathematical analysis of ECSG WT generator} torque ripple

To analyze torque ripple of the ECSG WT generator, the stator current harmonics that cause the 12thorder torque ripple are considered as an example. These harmonic currents include 11th-order negative sequence and 13th-order positive sequence components. Supposing stator phase A terminal voltage as $V_{a}=$ $V \sin (\omega t)$ and considering unity power factor operation of DBR, the 11th- and 13th-order harmonic currents of stator windings can be written as:

$$
\begin{aligned}
& i_{a(11)}=I_{11} \sin (11 \omega t), \\
& i_{b(11)}=I_{11} \sin (11 \omega t+2 \pi / 3), \\
& i_{c(11)}=I_{11} \sin (11 \omega t-2 \pi / 3),
\end{aligned}
$$

and:

$$
\begin{aligned}
& i_{a(13)}=I_{13} \sin (13 \omega t), \\
& i_{b(13)}=I_{13} \sin (13 \omega t-2 \pi / 3), \\
& i_{c(13)}=I_{13} \sin (13 \omega t+2 \pi / 3) .
\end{aligned}
$$

By transforming these harmonic currents to generator direct and quadratic axis components by dq0 transformation, the following results are obtained:

$$
\begin{aligned}
& i_{d(h)}=\left(I_{11}+I_{13}\right) \sin (12 \omega t), \\
& i_{q(h)}=-\left(I_{11}+I_{13}\right) \cos (12 \omega t) .
\end{aligned}
$$

On the other hand, torque equation of the generator is written as follows:

$$
T_{e}=\psi_{d} i_{q}-\psi_{q} i_{d}
$$

where magnetic flux components are:

$$
\psi_{d}=-L_{d} i_{d}+L_{a d} i_{f d}
$$

$$
\psi_{q}=-L_{q} i_{q}
$$

From Eqs. (A.3)-(A.5), the generator 12th-order torque ripple equation is obtained as follows:

$$
\begin{aligned}
T_{e(12)}= & {\left[\left(L_{d}-L_{q}\right)\left(I_{11}+I_{13}\right) \sin (12 \omega t)-L_{a d} i_{f d}\right] } \\
& \times\left(I_{11}+I_{13}\right) \cos (12 \omega t) .
\end{aligned}
$$

It is noted that the 12 th-order torque ripple of the generator is merely caused by 11 th- and 13 th-order harmonic currents of the stator windings.

\section{Biographies}

Ali Shamsnia is a $\mathrm{PhD}$ Candidate of Electrical Power Engineering at Sharif University of Technology, Tehran, Iran. He received his BSc degree from Tabriz University, Iran in 2008 and the MSc degree from Sharif University of Technology in 2010, both in Electrical Power Engineering. During 2010-2019, he worked as the technical manager for Mizan Ghostar Rayaneh, an accredited laboratory of National Institute of Standards and Industrial Research. His research interests include renewable energies and power quality.

Mostafa Parniani (Senior Member, IEEE) is a Professor of Electrical Engineering at Sharif University of Technology (SUT), Tehran, Iran. He received his BSc degree from Amirkabir University of Technology, Iran in 1987 and the MSc degree from SUT in 1990, both in Electrical Power Engineering. During 198890, he worked for Ghods-Niroo Consulting Engineers Company and for Electric Power Research Center (EPRC) in Tehran. Then, he obtained the PhD degree in Electrical Engineering from the University of Toronto, Canada in 1995. He was a visiting scholar at Rensselaer Polytechnic Institute, USA during 20052006. He has been a member of several national committees and councils in his field. His research interests include power system dynamics and control, applications of power electronics in power systems, and renewable energies. 